\section{In brief}

Psychiatrists launch campaign to help carers: A year long campaign has been launched to aid the estimated six million carers of people with mental health problems in the United Kingdom. The campaign, by the Royal College of Psychiatrists and the Princess Royal Trust for Carers, aims to help the $80 \%$ of carers who say that caring has had an adverse affect on their health.

Another suspected SARS case in China: A third suspected case of severe acute respiratory syndrome (SARS) has emerged in

Guangdong province, southern China, in a 35 year old man with fever and pneumonia. Preliminary tests for SARS were positive, and the man is now in isolation.

Netcare wins NHS bid: South African company Netcare has been awarded a contract to supply two new mobile treatment centres for cataract operations.

After agreeing to a price of nearly $10 \%$ lower than NHS costs, the centres will perform an additional 41600 procedures over the next five years.

Plant life threatened by herbal medicine: The worldwide boom in herbal medicine is endangering up to a fifth of wild medicinal plant species, threatening natural habitats and jeopardising the health of millions of people in developing countries, says a report in New Scientist (2004;181:10-1).

Doctors give wrong guidance on driving: Patients are being given the wrong advice on whether they can drive or not because doctors are failing to consult appropriate guidance, says the UK's Driver and Vehicle Licensing Agency. See www.dvla.gov.uk for up to date guidelines.

Violence is a health issue, says WMA: The World Medical Association's secretary general, Dr Delon Human, said that the association would provide members with training and ongoing advocacy for preventing violence. Speaking at a conference in Geneva, Switzerland, he encouraged medical associations to advocate violence prevention strategies and services for victims.

\title{
Inadequate regulations undermine India's health care
}

\section{Ganapati Mudur New Delhi}

The private sector dominates health care in India, but inadequate legislation and failure to enforce regulations are contributing to poor quality medical services, says a World Bank publication released in New Delhi last week.

Eighty per cent of spending on health in India is from personal funds, but existing laws do not ensure that private medical services maintain even minimum standards, says the report.

"Powerful medical lobbies have opposed government efforts to regulate the private sector," it says, adding that India's medical councils are not enforcing laws relating to registration and licensing of medical practitioners.

In a section on private healthcare services the report acknowledges problems that consumer health organisations have long complained about: doctors overprescribing drugs, recommending unnecessary investigations and treatment, and failing to provide appropriate information for patients.

It says there are no laws regulating the geographical distribution of healthcare providers and the types of technology to be made available, and it suggests that the influx of technology may have led to unreasonable use of equipment. Yet, despite such problems most people still choose the private sector, because of accessibility and shorter waiting times for diagnosis and treatment.

Health sector analysts say the private healthcare system in India should be segmented so that the relation between quality and prices of services can be examined. "We would probably find that some private sector establishments offer excellent quality at a high price," said Professor Subrata Chakraborty of the Indian Institute of Management, Lucknow, who analysed the private sector in India's largest state, Uttar Pradesh, for the report. "The typical consumer doesn't separate the two issues."

"The Indian Medical Association has consistently opposed any kind of regulation," said Ravi Duggal, coordinator of Mumbai's Centre for Enquiry into Health and Allied Themes, a nongovernmental organisation that has been long been campaigning for minimum standards.

A survey in Mumbai in the mid-1990s showed gross deficiencies in the quality of medical services. "There were clinics operating out of residential flats, with kitchens turned into operating theatres," said Dr Abhay Shukla, project coordinator at the centre.

Health Policy Research in South Asia: Building Capacity for Reform is available at www.worldbank.org/sar

\section{Risk of cancer from mobile phones is unclear}

Caroline White London

Recent evidence does not implicate the use of mobile phones in the development of cancer, finds an independent review published this week. But the body that commissioned the report is still recommending a precautionary approach to using them.

The advisory group's report,

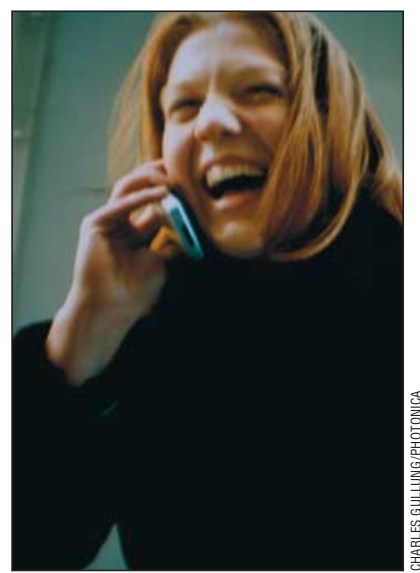

It's good to talk, but is it safe? commissioned by the United Kingdom's National Radiological Protection Board, says that the limitations of the research to date-and the fact that mobile phones have not been in widespread use for a long timemean that adverse health effects cannot be completely excluded.

The review came in response to a request from the government after the publication in May 2000 of the Stewart report on the health impact of mobile phones (BMJ 2000;320:1358).

The Independent Advisory Group on Non-ionising Radiation, led by Professor Anthony Swerdlow at the Institute of Cancer Research, London, assessed the recent experimental and epidemiological evidence on radiofrequency transmissions (microwaves) from all sources, particularly those associated with mobile phones and base stations.

Some studies have found possible adverse effects on brain function of exposure to microwaves at levels similar to those from mobile phone handsets. But the group regarded the overall evidence as inconclusive. Moreover, more recent, better quality, research did not corroborate the findings of earlier studies, suggesting that the emissions affected the movement of calcium ions in nervous system tissues.

"In aggregate, the research published since the [Stewart] report does not give cause for concern," concludes the review, saying that the weight of the evidence does not implicate microwave emissions at exposures below recommended levels.

But it cautions that the variable quality of the available research and relatively short term data mean that detrimental health effects cannot be ruled out completely.

"The possibility therefore remains that there could be health effects from exposure to radiofrequency fields below guideline levels; hence continued research is needed," it says.

The National Radiological Protection Board said "A precautionary approach to the development of mobile phone technology remains a justifiable approach."

Dr Michael Clark, scientific spokesman for the board, said "There is still uncertainty about the health effects," he said.

Health Effects From Radiofrequency Electromagnetic Fields can be accessed at www.nrpb.org/ publications 